\title{
NUMERICAL RESEARCH OF THE MATHEMATICAL MODEL FOR TRAFFIC FLOW
}

\author{
A.S. Konkina, South Ural State University, Chelyabinsk, Russian Federation, \\ konkinaas@susu.ru
}

\begin{abstract}
The problems of distribution of transport flows are currently relevant in connection with the increase in vehicles. In the 50s of the last century, the first macroscopic (hydrodynamic) models appeared, where the transport flow resembles the flow "motivated" compressible liquid. The scientific approach based on the Navier-Stokes system. The main idea of the scholars is consideration the hydrodynamic models on the grounds of interrelation between the transport flow and incompressible fluid. For modelling traffic flows we examine Oskolkov equation on the geometric graph, where the edge has two positive values corresponding to it "length" and "width". Certainly, in the context of mathematical model the values $l_{k}$ and $b_{k}$ are dimensionless, but for clarity it is convenient to imagine that $l_{k}$ is measured in linear metric units, for example, kilometers or miles, and $b_{k}$ is equal to the number of traffic lanes on the roadway in one direction. In terms of the Oskolkov model, we obtained a nonclassical multipoint initial-final value condition. We will study such a model using the idea and methods of the Sobolean equation theory. These notes describe a numerical experiment based on the Galerkin method for the Oskolkov equation with a multipoint initial-final condition on the graph.
\end{abstract}

Keywords: Oskolkov equation; geometric graph; multipoint initial-final condition; traffic flows.

\section{Introduction}

Despite the fact that a lot of time has passed since the appearance of the first works, according to a number of well-known experts in the field of mathematical modeling of traffic $[1,2]$, the problem of formation of not loaded and congestion situations has not yet been fully studied (and is similar to the problem of describing turbulent flows). Using the terminology proposed by B.S. Kerner, we can say that at the moment there is no generally accepted approach describing the behavior of motor vehicles in the synchronized flow area. That is, if the car flow is like liquids, the most difficult situation to simulate is the freezing liquid. Confirmation of this statement is the fact that different teams involved in the modeling of traffic flows, as a rule, use different models: from the Lighthill-Whitham model (A.A. Kurzhanski [3]), ending with models in which each driver is characterized by its variational principle (I.A. Lubashevsky [4]). Today, there are many approaches to solving this problem $[5,6]$.

Our study is based on the model considered by A.B. Kurzhanski, who was the first to note the undoubted properties of the transport flow as viscosity and incompressibility. Developing this approach, it is proposed to replace the Navier-Stokes equations with the more general Oskolkov equations, which take into account not only the viscosity and incompressibility of the flow, but also its elasticity. Indeed, when the traffic light is switched on, the vehicles do not stop immediately, but smoothly reduce the speed up to the stop, accumulating in front of the stop line. Similarly, when the traffic light signal is switched on, vehicles do not start instantly and simultaneously, but move from one place to another 
gradually gaining speed.Thus, the transport flow shows the effect of retardation inherent in viscoelastic incompressible liquids. Secondly, Oskolkov equations are considered on the geometric graph, the main difference of which is the statement in conformity to each edge of the two positive numbers corresponding (in our case) to its "length" and "width" [7]. We will study such a model using the idea and methods of the Sobolev equation theory. The solution to this problem is presented in the article [8].

\section{Problem Statement}

Let us consider the finite ordered set of finite coherent oriented graphs $\mathbf{G}=\mathbf{G}(\mathcal{V}, \mathcal{E})$, where $\mathcal{V}=\left\{V_{j}\right\}$ is the set of vertices, and $\mathcal{E}=\left\{E_{k}\right\}$ is the set of edges, moreover, each edge $E_{k}$ of each graph $\mathbf{G}$ corresponds to two numbers $l_{k}$ and $b_{k} \in \mathbb{R}_{+}$, responsible to its "length" and "width" respectively. Certainly, in the context of mathematical model the values $l_{k}$ and $b_{k}$ are dimensionless, but for clarity it is convenient to imagine that $l_{k}$ is measured in linear metric units, for example, kilometers or miles, and $b_{k}$ is equal to the number of traffic lanes on the roadway in one direction. On each edge of $E_{k}$ of each graph G define the linear Oskolkov equation [9]

$$
\lambda u_{k t}-u_{k t x x}=\nu u_{k x x}+f_{k} .
$$

Here $u_{k}=u_{k}(x, t), x \in\left[0, l_{k}\right], t \in \overline{\mathbb{R}}_{+}\left(\equiv\{0\} \cup \mathbb{R}_{+}\right)$characterizes the average speed of traffic flow on $E_{k} ; f_{k}=f_{k}(x, t),(x, t) \in\left[0, l_{k}\right] \times \overline{\mathbb{R}}_{+}$, corresponds to the (average) force that causes the wheels of vehicles to spin. The coefficients $\lambda$ are equal to the unit divided by the retardation coefficient, which can take negative values, so we consider $\lambda \in \mathbb{R}$. The coefficient $\nu$ is responsible for the viscosity of the transport flow, i.e. for its ability to "dampen" sharp speed differences; within the meaning $\nu \in \mathbb{R}_{+}$.

Let's find the conditions that connect the solutions of different equations (1) in the vertices of the graph. Since in this model the vertices are associated with crossroads, the conditions for the velocity mode at the crossroad passage are very important. For the first consider continuity condition

$$
u_{k}(0, t)=u_{m}\left(l_{m}, t\right), \forall E_{k} \in E^{\alpha}\left(V_{j}\right), \forall E_{m} \in E^{\omega}\left(V_{j}\right) .
$$

Here $E^{\alpha(\omega)}\left(V_{j}\right)$ denotes the set of edges of the graph $\mathbf{G}$, emerging from the vertex $V_{j}$ (entering the vertex $V_{j}$ ). In terms of our model, condition (2) means that the speed of the vehicle entering the crossroad must be equal to the speed of the exit. This condition is quite natural, otherwise there may be congestion at crossroads or accidents. Besides, we need thread balance condition

$$
\sum_{E_{k} \in E^{\alpha}\left(V_{j}\right)} b_{k} u_{k x}(0, t)-\sum_{E_{m} \in E^{\omega}\left(V_{j}\right)} b_{m} u_{m x}\left(l_{m}, t\right)=0,
$$

which requires that the number of vehicles leaving for the crossroad is equal to the number of vehicles leaving the crossroad. Take $\tau_{z} \in \overline{\mathbb{R}_{+}}$, such that $\tau_{z-1}<\tau_{z}$, where $z=\overline{1, n}$. Note that we can supplement the condition

$$
P_{z}\left(u\left(\tau_{z}\right)-u_{z}\right)=0, z=\overline{0, n},
$$

where $P_{z}$ is the relatively spectral projectors [10].

We introduce the Hilbert spaces $\mathbf{L}_{\mathbf{2}}(\mathbf{G})=\left\{g=\left(g_{1}, g_{2}, \ldots, g_{k}, \ldots\right): g_{k} \in L_{2}\left(0, l_{k}\right)\right\}$, $\mathfrak{U}(\mathbf{G})=\left\{u=\left(u_{1}, u_{2}, \ldots, u_{k}, \ldots\right): u_{k} \in W_{2}^{1}\left(0, l_{k}\right)\right\}$.

Theorem 1. [8] For any $\lambda, \nu \in \mathbb{R}_{+}, u_{z} \in \mathfrak{U}(\mathbf{G}), z=\overline{1, n}$, there exists a unique solution $u \in C^{\infty}\left(\mathbb{R}_{+} ; \mathfrak{U}(\mathbf{G})\right)$ of problem (1) - (4). 


\section{Numerical Algorithm and Experiment}

Consider the Oskolkov model on a two-edge graph with a multipoint initial-final condition. This problem can be considered as a transport stream. The graph is presented as a road with an intersection, where each edge is separated by a traffic light.

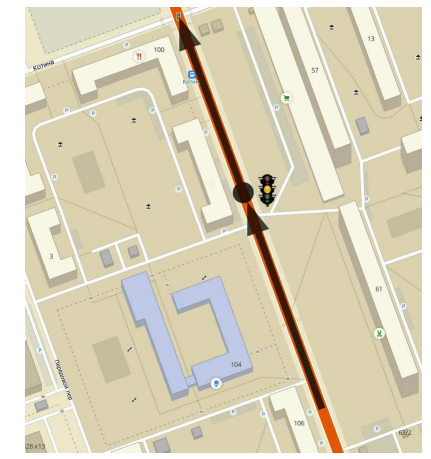

Fig. 1. Crossroads map

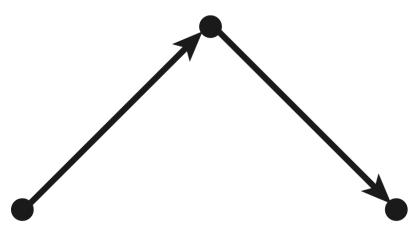

Fig. 2. Graph G

In experiment, we introduce the values of auxiliary parameters, where $\nu$ and $\lambda$ are the coefficients, $k$ is the number of edges, $l$ is the length of the edge. Let be $\lambda=10 ; \nu=$ $1 ; f_{k}(x)=0 ; l_{1}=l_{2}=\pi$. Consider the linearized Oskolkov equations on a two-edge graph

$$
\begin{aligned}
& 10 u_{1 t}-u_{1 t x x}=u_{1 x x}, \\
& 10 u_{2 t}-u_{2 t x x}=u_{2 x x},
\end{aligned}
$$

conditions (2), (3) will take the form

$$
\left\{\begin{array}{r}
u_{1}(0, t)=u_{2}(0, t) \\
u_{1 x}(\pi, t)=0 \\
u_{2 x}(\pi, t)=0 \\
u_{1 x}(0, t)+u_{2 x}(0, t)=0
\end{array}\right.
$$

Eigenfunctions and eigenvalues of the Sturm-Liouville problem on the indicated graph would be found

$$
\left\{\begin{array}{r}
X_{1}^{\prime \prime}+\lambda X_{1}=0 \\
X_{2}^{\prime \prime}+\lambda X_{2}=0 \\
X_{1}\left(l_{1}\right)=X_{2}(0) \\
X_{1}^{\prime}\left(l_{1}\right)-X_{2}^{\prime}(0)=0 \\
X_{1}^{\prime}(0)=0 \\
X_{2}^{\prime}\left(l_{2}\right)=0
\end{array}\right.
$$

The Sturm-Liouville problem on the indicated graph $\mathbf{G}$ has eigenvalues $\lambda_{k}=\left(\frac{\pi k}{l_{1}+l_{2}}\right)^{2}$, $k=\{0\} \cup \mathbb{N}$, which correspond to the following eigenfunctions

$$
X^{k}(x)=\left(X_{1}^{k}(x), X_{2}^{k}(x)\right)=\left(C_{1} \cos \left(\frac{\pi k}{l_{1}+l_{2}} x\right), C_{1} \cos \left(\frac{\pi k}{l_{1}+l_{2}}\left(x+l_{1}\right)\right)\right), k=\{0\} \cup \mathbb{N} .
$$

We consider the problem with a two-point initial-final condition

$$
\sum_{k: \mu_{k} \in \sigma_{0}^{L}(M)}\left\langle\left(u\left(\tau_{0}\right)-u_{0}\right), X_{0}^{k}\right\rangle X^{k}=\sum_{k: \mu_{k} \in \sigma_{1}^{L}(M)}\left\langle\left(u\left(\tau_{1}\right)-u_{1}\right), X_{1}^{k}\right\rangle X^{k}=0,
$$


when

$$
\begin{gathered}
\sigma_{0}^{L}(M)=\left\{\mu_{k}=\frac{1}{10-\lambda^{k}}: k>4\right\}, \\
\sigma_{1}^{L}(M)=\left\{\mu_{k}=\frac{\alpha}{\lambda-\lambda^{k}}: k=\overline{0,4}\right\}=\left\{\frac{1}{10}, \frac{4}{39}, \frac{1}{9}, \frac{4}{31}, \frac{1}{6}\right\}, \\
u_{0}=\left(5 \sin \left(x+\frac{\pi}{2}\right)-2,5 \sin \left(4 x+\frac{\pi}{2}\right)-2\right), \\
u_{1}=\left(10 \sin \left(x-\frac{\pi}{2}\right)+3,10 \sin \left(2 x-\frac{\pi}{2}\right)+3\right) .
\end{gathered}
$$

Based on the data above, we obtained and realized the program for numerical solution to problem (1) - (4) in the Maple 2017. The created program allows to find the approximate solution to problem (1) - (4) on the geometrical graph at any initial data and at any values of $\lambda, \nu$ and display the graph of the approximate solution. In the program we can control the accuracy of the Galerkin sum coefficients. The algorithm built into the Maple 2017 algorithm for solving the system of differential equations and other built-in operators and algorithms were also used in the implementation of the algorithm.

Describe the algorithm in more detail. Each block of the algorithm corresponds to one step:

1 step. After the beginning of the program execution to enter the number of components of the Galerkin sum $N$, coefficients $\lambda, \nu$, initial conditions $u_{z}, \tau_{z}$, the number of graph edges and their length.

2 step. Generation of an approximate solution and optimal control in the form

$$
\begin{aligned}
& u_{0}(t, x)=\sum_{k=1}^{N} a_{k}(t) X_{0}^{k}(x) \\
& u_{1}(t, x)=\sum_{k=1}^{N} a_{k}(t) X_{1}^{k}(x)
\end{aligned}
$$

respectively, where $X^{k}$ is orthonormal in the sense of $L_{2}(\mathbf{G})$ family of eigenfunctions of the Sturm-Liouville problem on a graph G [11]. Substituting the form of the solution into the Oskolkov equation, scalarly multiplying the differential equations obtained in the previous step by the functions $X_{0}^{k}, X_{1}^{k}, k=1, \ldots, N$, compiled a system of differential equations we obtain a differential equation for unknowns $a_{k}(t)$.

3 step. For each edge, to constitute multipoint initial-final conditions for the system of equations.

4 step. The degeneracy condition of the system of equations is verified. If it does not hold, then we have a system of ordinary differential equations.

5 step. Initial functions for each edge to decompose in the Galerkin sum, based on them, the initial conditions for the system of equations to obtain at the previous step are determined. 6 step. The resulting system of homogeneous differential equations with initial data to solve by the method embedded in the Maple 2017 package.

7 step. The solution obtained for each edge to display on the screen as a function and as a graph. 
We obtain a solution of the form

$$
u(t)=\sum_{\mu_{k} \in \sigma_{0}^{L}(M)} e^{\mu_{k}\left(t-\tau_{0}\right)}\left\langle u_{0}, X_{0}^{k}\right\rangle_{L_{2}(\mathbf{G})} X_{0}^{k}+\sum_{\mu_{k} \in \sigma_{1}^{L}(M)} e^{\mu_{k}\left(t-\tau_{1}\right)}\left\langle u_{1}, X_{1}^{k}\right\rangle_{L_{2}(\mathbf{G})} X_{1}^{k}
$$

The solution to this problem is seen in the figures. The resulting graph of the change in speed at the intersection.

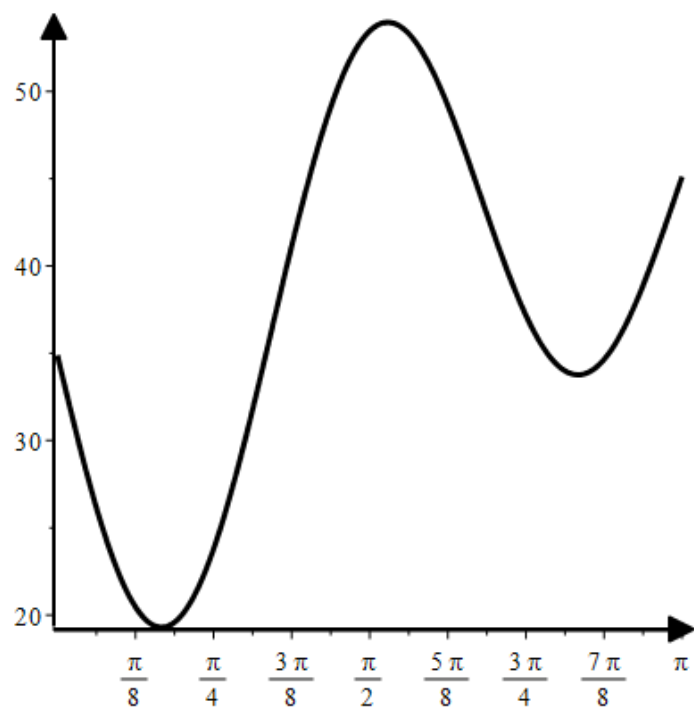

Fig. 3. Edge 1

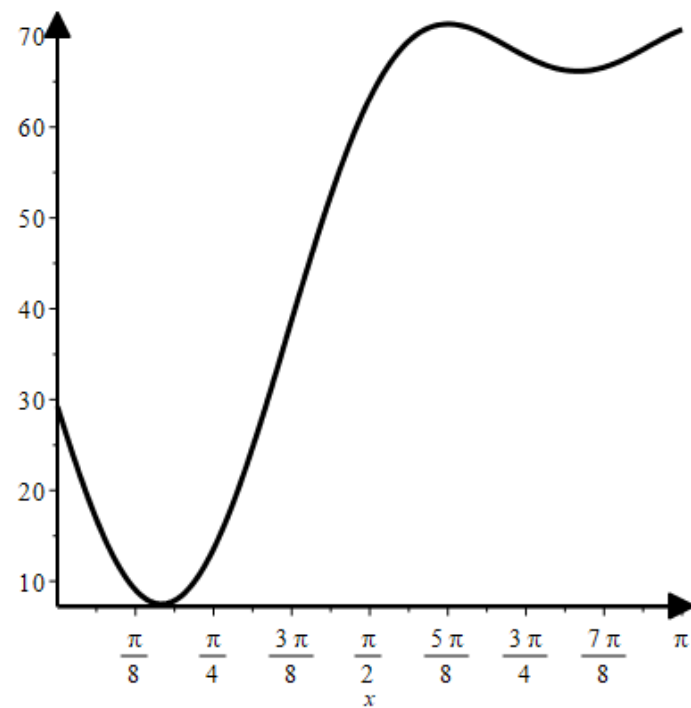

Fig. 4. Edge 2

Acknowledgement. The work was supported by Act 211 Government of the Russian Federation, contract no. 02.A03.21.0011.

\section{References}

1. Hwang F.K., Richards D., Winter P. The Steiner Tree Problem. Amsterdam, Elsevier Science Publishers, 1992.

2. Siebel F., Mauser W. On the Fundamental Diagram of Traffic Flow. SIAM Journal on Applied Mathematics, 2006, no. 66, pp. 1150-1162.

3. Kurzhanski A.A., Kurzhanski A.B. Smart City Crossroads. Computer Research and Modeling, 2015, vol. 10, no. 3, pp. 347-358. DOI:10.20537/2076-7633-2018-10-3-347-358 (in Russian)

4. Zgonnikov A., Lubashevsky I. Double-Well Dynamics of Noise-Driven Control Activation in Human Intermittent Control: The Case of Stick Balancing. Cognitive Processing, 2015, vol. 16, no. 4, pp. 351-358. DOI: 10.1007/s10339-015-0653-5

5. Gorodokin V., Almetova Z., Shepelev V. Algorithm of Signalized Crossroads Passage Within the Range of Permissive-to-Restrictive Signals Exchange. Transportation Research Procedia, 2018, vol. 36, pp. 225-230. DOI: 10.1016/j.trpro.2017.01.05910.1007/s10339-015-0653-5

6. Banasiak J., Falkiewicz A., Namayanya P. Asymptotic State Lumping in Transport and Diffusion Problems on Networks with Applications to Population Problems. Mathematical Models and Methods in Applied Sciences, 2016, vol. 26, no. 2, pp. 215-247. DOI: $10.1142 / \mathrm{S} 0218202516400017$ 
7. Oskolkov A. P. Nonlocal Problems for Some Class Nonlinear Operator Equations Arising in the Theory Sobolev Type Equations. Zapiski LOMI, 1991, vol. 198, pp. 31-48. (in Russian)

8. Sviridyuk G.A., Zagrebina S.A., Konkina A.S. The Oskolkov Equations on the Geometric Graphs as a Mathematical Model of the Traffic Flow. Bulletin of the South Ural State University. Series: Mathematical Modelling, Programming and Computer Software, 2015, vol. 8 , no. 3 , pp. $148-154$. DOI: $10.14529 / \mathrm{mmp} 1503010$

9. Oskolkov A.P. Nonlocal Problems for Some Class Nonlinear Operator Equations Arising in the Theory Sobolev Type Equations. Zapiski LOMI, 1991, vol. 198, pp. 31-48. (in Russian)

10. Zagrebina S.A., Konkina A.S. The Multipoint Initial-Final Value Condition for the NavierStokes Linear Model Bulletin of the South Ural State University. Series: Mathematical Modelling, Programming and Computer Software, 2015, vol. 8, no. 1, pp. 132-136. DOI: $10.14529 / \mathrm{mmp} 150111$

11. Bayazitova A.A. On the Generalized Boundary-Value Problem for Linear Sobolev Type Equations on the Geometric Graph. Bulletin of the South Ural State University. Series: Mathematics. Mechanics. Physics, 2018, vol. 10, no. 3, pp. 5-11.

Received July 9, 2019

УДК 517.9

DOI: $10.14529 / \mathrm{mmp} 190411$

\section{ЧИСЛЕННОЕ ИССЛЕДОВАНИЕ МАТЕМАТИЧЕСКОЙ МОДЕЛИ ТРАНСПОРТНОГО ПОТОКА}

$\boldsymbol{A}$. $\boldsymbol{C .}$ Конкина, Южно-Уральский государственный университет, г. Челябинск, Российская Федерация

Проблемы распределения транспортных потоков являются в настоящее время актуальными в связи с увеличением транспортных средств. В 50-е годы прошлого века появились первые макроскопические (гидродинамические) модели, в которых транспортный поток уподобляется потоку «мотивированной» сжимаемой жидкости. Ранее изучался подход, в основе которого лежит система Навье - Стокса, где транспортный поток уподобляется несжимаемой жидкости, и, как следствие, рассматриваются гидродинамические модели. Для моделирования транспортного потока в данной работе будем рассматривать уравнения Осколкова на геометрическом графе, где ребро имеет два положительных значения, отвечающих его «длине» и «ширине». Безусловно, в контексте математической модели величины $l_{k}$ и $b_{k}$ безразмерны, однако для наглядности удобно представлять, что $l_{k}$ измеряется в линейных метрических единицах, например, километрах или милях, а вот $b_{k}$ равно количеству полос движения на проезжей части в одну сторону. Для рассматриваемой модели поставлено неклассическое многоточечное начально-конечное условие. Изучение такой модели будет проводиться с использованием идеи и методов теории уравнений соболевского типа. В данной работе описывается численный эксперимент на основе метода Галеркина для уравнения Осколкова с многоточечным начально-конечным условием на графе.

Ключевые слова: уравнения Осколкова; геометрический граф; многоточечное начально-конечное условие; транспортные потоки.

Вестник ЮУрГУ. Серия «Математическое моделирование

и программирование» (Вестник ЮУрГУ ММП). 2019. Т. 12, № 4. С. 128-134 


\section{Литература}

1. Hwang, F.K. The Steiner Tree Problem / F.K. Hwang, D. Richards, P. Winter. - Amsterdam: Elsevier Science Publishers, 1992.

2. Siebel, F. On the Fundamental Diagram of Traffic Flow / F. Siebel, W. Mauser // SIAM Journal on Applied Mathematics. - 2006. - № 66. - P. 1150-1162.

3. Куржанский, А.А. Перекресток в умном городе / А.А. Куржанский, А.Б. Куржанский // Компьютерные исследования и моделирование. - 2015. - Т. 10, № 3. - С. 347-358.

4. Zgonnikov, A. Double-Well Dynamics of Noise-Driven Control Activation in Human Intermittent Control: The Case of Stick Balancing / A. Zgonnikov, I. Lubashevsky // Cognitive Processing. - 2015. - V. 16, № 4. - P. 351-358.

5. Gorodokin, V. Algorithm of Signalized Crossroads Passage within the Range of Permissiveto-Restrictive Signals Exchange / V. Gorodokin, Z. Almetova, V. Shepelev // Transportation Research Procedia. - 2018. - V. 36. - P. 225-230.

6. Banasiak, J. Asymptotic State Lumping in Transport and Diffusion Problems on Networks with Applications to Population Problems / J. Banasiak, A. Falkiewicz, P. Namayanya // Mathematical Models and Methods in Applied Sciences. - 2016. - V. 26, № 2. - P. 215-247.

7. Осколков, А.П. Нелокальные проблемы для одного класса нелинейных операторных уравнений, возникающих в теории уравнений С.Л. Соболева / А.П. Осколков // Записки научных семинаров ЛОМИ. - 1991. - Т. 198. - С. 31-48.

8. Свиридюк, Г.А. Уравнения Осколкова на геометрических графах как математическая модель дорожного движения / Г.А. Свиридюк, С.А. Загребина, А.С. Конкина// Вестник ЮУрГУ. Серия: Математическое моделирование и программирование. - 2015. - Т. 8, № 3. - C. $148-154$.

9. Осколков, А.П. О некоторых нестационарных линейных и квазилинейных системах, встречающихся при изучении движения вязкой жидкости / А.П. Осколков // Записки научных семинаров ЛОМИ. - 1976. - Т. 59. - С. 133-177.

10. Zagrebina, S.A. The Multipoint Initial-Final Value Condition for the Navier - Stokes Linear Model / S.A. Zagrebina, A.S. Konkina // Вестник ЮУрГУ. Серия: Математическое моделирование и программирование. - 2015. - Т. 8, № 1. - С. 132-136.

11. Баязитова А.А. Об обобщенной краевой задаче для линейных уравнений соболевского типа на графе / А.А. Баязитова // Вестник ЮУрГУ. Серия: Математика. Механика. Физика. - 2018. - Т. 10, № 3. - С. 5-11.

Александра Сергеевна Конкина, ассистент, кафедра «Уравнения математической физики», Южно-Уральский государственный университет (г. Челябинск, Российская Федерация), konkinaas@susu.ru.

Поступила в редакцию 9 июля 2019 г. 